\title{
Persona Rights for User-Generated Content: A Normative Framework for Privacy and Intellectual Property Regula- tion
}

\author{
Tamara Shepherd
}

Concordia University, Montréal, Canada, tamara.shepherd@gmail.com

Abstract: This article introduces the term "persona rights" as a normative conceptual framework for analyzing the language of regulatory debates around privacy and intellectual property online, mainly from a Canadian perspective. In using the concept of persona rights to interrogate and critique the current limitations of regulatory discourses in protecting user rights online, the legal implications of persona rights law are translated into more conceptual terms. As a normative framework, persona rights is shown to be useful in addressing the gaps in regulatory understandings of privacy and intellectual property - particularly in spaces for user-generated content (UGC) - and in suggesting how policy might be written to account for user rights to the integrity of identity in commercial UGC platforms.

Keywords: Rights, Policy, User-generated Content, Regulation, Discourse, Identity, Privacy, Intellectual Property, Internet Law

Acknowledgement: This research was supported by a grant from the Social Sciences and Humanities Research Council of Canada. Earlier versions of the article benefitted from feedback graciously offered by Leslie Regan Shade, Matt Stahl, and an anonymous reviewer

Following from the ideals of internet regulation in the public interest, and particularly from a Canadian point of view, this paper proposes "persona rights" as a framework for considering user rights in online spaces designed for individuals to contribute their own content, or user-generated content (UGC). As a legal concept, the term persona rights refers to an individual's control over any commercial uses of her or his identity in social web platforms. 1 It thus rests on the premise that individual web users should have recourse to legal and regulatory protection of their rights to the integrity and dignity of their personal identities online. With mandates to protect user-citizen rights, developed nations such as Canada, the U.S. and the UK have shown a growing interest in safeguarding personal identity online, as it is continually defined through policy debates about privacy and intellectual property rights. This paper presents a rhetorical analysis of such debates in recent reports from the Canadian Radio-television Telecommunications Commission (CRTC), the U.S. Federal Trade Commission (FTC), the UK's Ofcom and the international Organisation for Economic Co-operation and Development (OECD), framed through persona rights as a normative standard for identifying and addressing some critical gaps in regulatory understandings of privacy and intellectual property. The current moment of commercial, contract-based regulation of UGC platforms is interrogated here according to what the persona rights framework identifies as crucial issues of user rights and the integrity of identity in user-generated content.

The definition of persona rights used in this paper follows from William McGeveran's legal formulation, where he argues that online social marketing practices entail potential threats to user rights, which might be protected under persona rights law that "transcends the narrower focus of other paradigms on protecting information privacy or preventing misleading advertising" (2009, 1154). In addition to the perhaps more familiar understandings of how online social platforms capitalize on private personal information and users' intellectual property, the persona rights rationale sees social networks as built on the premise of endorsement. Similar to celebrity endorsement, user endorsement - comprised of both users' private personal and network information and their work in creating UGC - be subject to "two related but distinct legal claims: the tort of appropriation and the right of publicity" in U.S. law (McGeveran 2009, 1149). By protecting against unauthorized commercial uses of one's identity (the tort of appropriation) and maintaining monopoly control over one's own image (the right of publicity), these two legal instruments serve the function of recognizing the integrity and dignity of personal identity, in light of commercial exploitation, as sanctioned by the state.

\footnotetext{
1 "Social web platforms" refers mainly to social network sites, but also more broadly to websites that integrate UGC.
} 
Some limitations of persona rights law include the significant challenge of proving dignitary, as opposed to purely monetary, harm suffered from commercial abuses of persona rights. While the impact of dignitary harm on an individual basis might be too abstract or too small to prove; "compounded through the entire society, however, a pervasive loss of identity control could be troubling" (McGeveran 2009, 1154). In addition to the limitation of scale here, there are jurisdictional considerations to be made when it comes to any legal mode of rights protection. While in Canada, the tort of appropriation of personality represents an admissible legal claim to commercial uses of one's image, the right of publicity is not recognized in the same way as it is in the U.S., where celebrities retain a monopoly over any uses of their image (Hamilton 2009, 213). Yet despite this complication to a direct Canadian translation of persona rights law, McGeveran's idea is useful here primarily as a conceptual rather than strictly legal paradigm. The concept of persona rights contributes a unique and urgent normative framework for addressing the ways that social web platforms potentially encroach on rights pertaining to personal dignity and commercial value, articulated together as persona rights of privacy and intellectual property.

This paper offers an examination of privacy and intellectual property as persona rights, mitigated by the context of UGC on social web platforms. The term platform is important here; as Tarleton Gillespie contends, "Whatever possible tension there is between being a 'platform' for empowering individual users and being a robust marketing 'platform' and being a 'platform' for major studio content is elided in the versatility of the term and the powerful appeal of the idea behind it" $(2010,358)$. So while social web platforms promise a level playing field for user creativity and expression, they are also bound by commercial imperatives and proprietary cultural production. This context provides the backdrop against which to discuss the parameters of user rights in UGC, framed through the lens of persona rights.

In what follows, I examine a group of regulatory reports in terms of how they articulate persona rights as part of emerging policy frameworks for UGC. Explicit discussion of Canadian new media regulation in terms of citizenship figures most prominently in recent reports from the federal regulatory body, the CRTC, in line with the organization's mandate to "ensure that both the broadcasting and Telecommunications systems serve the Canadian public" (CRTC 2009). The Commission's regulatory decisions are primarily delivered according to the Broadcasting Act and the Telecommunications Act, both of which face challenges from the ambivalent position of new technologies and practices, such as UGC. Recent CRTC reports, like Perspectives on Canadian Broadcasting in New Media (2008) and Navigating Convergence (2010), are intended to address these challenges, through dealing with a host of regulatory concerns about new media. Such concerns include policy issues around the persona rights of privacy and intellectual property, which in Canada are often influenced by regulatory trends in both the U.S. and the UK, as well as by research from the OECD. As such, recent reports, Protecting Consumers in the Next Tech-ade (FTC 2008), Social Networking: A Quantitative and Qualitative Research Report into Attitudes, Behaviours and Use (Ofcom 2008) and Participative Web and User-Created Content: Web 2.0, Wikis and Social Networking (OECD 2007) are discussed here alongside the Canadian examples.

This set of documents tends to reflect and reinforce the distinctions between online privacy control over the disclosure and integrity of personal information online - and intellectual property control over the distribution of proprietary creative work - evidencing the need for a concept like persona rights that links privacy and intellectual property issues through the endorsement logic that subtends commercial UGC platforms. Persona rights thus offers the heuristic value of re-framing privacy and intellectual property as inextricable concerns, both in a commercial context and in the broader sense of online sociality as an element of contemporary citizenship. So while issues of privacy and intellectual property serve as key nodes to examine within the policy literature, they also invoke a broader identity rights perspective on practices of socialization, commerce and cultural production online.

In discussing how persona rights might fit into these overarching ecologies of UGC, the paper's first section discusses privacy as a persona right, leading into a discussion of endorsement as the key context for tying critical accounts of online privacy to those of intellectual property. In the second section, a discussion of intellectual property as a persona right highlights how the appropriation of users' creativity toward promotional aims maps onto regulatory considerations of original and derivative works in copyright protection. By making these ties between normative ideals around privacy and intellectual property, the following examination of the persona rights concept points toward ways that privacy and intellectual property in commercial spaces should be protected by emergent legislation. As such, the urgency of regulatory protection of persona rights demands further inquiry into its implications as a normative framework for users' rights online. 


\section{Persona Rights and Privacy}

McGeveran's account of persona rights law emerges from an analysis of social network sites (SNSs), such as Facebook and MySpace, in terms of how their marketing practices revolve around personalized promotional messages disseminated to a user's network of friends. Increasingly sophisticated promotional targeting methods on SNSs - particularly those like Facebook Connect, which culls user preferences from across the Web by integrating Facebook profiles with external sites - raise issues around disclosure, identity and endorsement in a social marketing practice that "falls through the cracks between several different sources of possible legal regulation" (McGeveran 2009,1108 ). More broadly speaking, the privacy concerns raised here implicate what Christena Nippert-Eng frames as the integrity of the self in attention economies like SNSs, where "the problem of achieving privacy, of controlling one's accessibility, agenda, and attention, has taken on new urgency" $(2011,169)$. As she points out, new communication technologies expand people's social territories, requiring greater attention to their borders in light of how such territories delineate expectations of personal privacy. The category of the person is central here, as it is for McGeveran, since negotiating privacy involves bumping up against asymmetrical power relationships in these social territories. In the context of SNSs, micro power relationships within local networks are contained within the larger commercial imperative of the sites themselves, where social marketing practices work to circumscribe the legal recourse of the "persona" within the logic of endorsement. This section addresses the question of how the persona rights perspective thus seeks protection of user privacy online by fortifying the integrity of individual identity control in SNSs.

According to a persona rights imperative, privacy concerns revolve around the integrity of personal information as it is bound up in the commercial endorsement function of online social platforms. To this end, a persona rights framework highlights informational, network or data privacy, the privacy of personally identifying information as it gets collected, bought and sold through internet marketing practices. As the Office of the Privacy Commissioner (OPC) of Canada has claimed, "the practice of constructing profiles and drawing inferences based on social networking information that individuals post poses a range of risks to individuals' privacy (and potentially other fundamental rights)" (OPC 2011, 18). Informational privacy can thus be distinguished from social privacy - the way users manage the disclosure of information to their networks of friends - which tends to be more of an immediate privacy concern for most people (e.g. Raynes-Goldie, 2010; Livingstone 2008,408 ). The relative invisibility of informational privacy - who is buying and selling users' personal information - makes it potentially more difficult to hold up to normative standards around the integrity of personal information, such as those suggested by the persona rights paradigm.

\subsection{Informational Privacy}

Definitions of privacy as a right or civil liberty have shifted along with changes in technology that re-shape the contours of social interaction. For instance, the earliest legal concept of privacy as a right in the U.S., framed by Samuel Warren and Louis Brandeis (1890) as "the right to be let alone," was developed in response to new practices of public photography. In the context of networked technologies, the idea of a right to privacy has remained a key normative concept that requires revision alongside the development of new technologies, infrastructures and practices of sociality (Kerr et al. 2009, xxvi; Lawson 1999; Agre and Rotenberg 1997; Introna 1997). In this shifting context, the privacy of personal information has taken on greater importance as a persona right amid an erosion of informational privacy engendered by the increasing penetration of data-based technologies (Allen 1999; Tavani 2008; Debatin et al. 2009). Informational privacy has been specifically critiqued from the point of view of commercial exploitation of personal data, where pervasive online surveillance of user information and behavior has resulted in "the reconceptualization of privacy in the consumer's mind from a right or civil liberty to a commodity that can be exchanged for perceived benefits" (Campbell and Carlson 2002, 588; see also: Gates and Magnet, 2007). The threat that the commodification of informational privacy poses to the integrity of the person as inalienable subject - as indicated in the persona rights concept - implicates an urgent moral or normative framing of the person as constituted by information (Floridi 2005), and thus as entitled to persona rights according to contemporary conceptions of digital citizenship.

Yet across the policy documents examined here, mentions of informational privacy are rare among discussions of social privacy as the most salient privacy issue in social network sites. One way of framing the apparent privileging of social over informational privacy as both users' and regulators' primary concern is through Helen Nissenbaum's concept of "contextual integrity" (2004; 2010). For Nissenbaum, violations of privacy occur when certain situational norms are transgressed. These norms are always contingent, and include multiple dimensions: "the role of agents 
receiving information; their relationships to information subjects; on what terms the information is shared by the subject; and the terms of further dissemination" (Nissenbaum 2004, 137-138). This framework highlights how, for most users, contextual integrity invokes their immediate social context as opposed to broader commercial substrates of social networking.

For regulators, an emphasis on social privacy serves the additional contextual function of obscuring how the commercial contracts that underpin social spaces online often threaten users' persona rights in a broader way. As such, and despite people's work of managing their privacy in relation to various audiences - friends, strangers, family members and employers - the control that they are actually able to exert through privacy settings is mitigated by the platforms' commercial imperative to collect personal data, using it according to the legal stipulations in site privacy policies. On SNSs and other UGC platforms, privacy architectures tend to be designed for commercial purposes, where corporate marketers comprise the unseen audience for personal information.

In its emphasis on the commercial application of all personal information and content contributed to social online spaces, persona rights offers a way of rethinking social privacy as always already inflected by informational privacy. A persona rights perspective should thus be integrated into current regulatory discourses that tend to frame the issue of strangers having access to users' personal information as a primarily social risk, without even mentioning the risk of corporations or governments collecting personal data for use in targeting and profiling. In Canada, the OPC is doing important work in this regard, emphasizing how SNS users "tend to think they are among friends and are not acting as 'consumers"', despite the fact that the primary audience for their information as indicated in the privacy policies of SNSs - is made up of commercial actors. The OPC sees this practice in terms of how "the distinction between our social interactions and our 'role' as consumers is disappearing. We are being turned into 'always on' consumers" (OPC 2011, 18).

Aside from the OPC's attention to the threats to informational privacy posed by SNS marketing practices, most regulators have not sufficiently addressed such threats. This reticence can be seen as an extension of the neoliberal context from which the reports emerge, where business and industry stakeholders exert pressure on governments to exercise the related policy strategies of deregulation, privatization and globalization that run counter to the public interest (Pickard 2007, 118). For instance, the single mention of informational privacy in the OECD report is nestled in the middle of the section on social privacy concerns, and it states: "In principle, information which is not displayed publicly is protected and not sold to third parties. In the case of a merger or acquisition by a third party, however, this information is an asset which is part of the transaction and which is handed over to the acquirer. There may also be cases of data leakages which could be due to the nature of the information and pictures prove particularly damaging, although so far little is known about such cases which may have occurred in the context of UCC [user-created content] sites" ${ }^{2}$ (OECD 2007, 56).

Effectively, this statement works to minimize the threat to personal privacy posed by commercial access to information - which makes sense in the context of the OECD's role as an economic development organization that seeks to bolster the economic potential of UGC. Nonetheless, as a model for "monetising the audience" through the implementation of business models that "may involve the selling of anonymised information about users and their tastes and behaviour to market research and other firms", what the OECD is promoting here is essentially a breach of informational privacy (OECD 2007, 27). The report's language around this issue works to downplay the risks associated with informational privacy by wording it as purely an order of business, as a fiduciary "transaction."

A similar rhetorical move can be seen in the CRTC's Perspectives report, which begins and ends its discussion of privacy with the disclaimer that "Privacy and accessibility issues raised by stakeholders are important but fall outside the scope of the research and consultation undertaken for this document" (CRTC 2008, 12). The report then goes on to suggest that one of the benefits of more active users/audiences online comes from commodifying user data: "Content providers can exploit the interactivity of new platforms to strengthen loyalty to programs and artists and to build upon the capabilities of new platforms to deliver more granular audience data that can generate higher advertising revenues through targeting. By extending the reach of these providers beyond what was possible in the traditional broadcast environment, these new platforms have provided new opportunities to generate global sales and brand recognition" (CRTC 2008, 46).

As in the OECD report, the commercial function of gathering user data is framed in technical terms, where the platforms' ability to "deliver more granular audience data" constitutes a beneficial new opportunity for broadcast businesses to compete on a global scale. The issue of privacy in this

\footnotetext{
${ }^{2}$ The term "UCC," as used in the OECD report, is treated as synonymous with UGC.
} 
data collection remains absent, privileging economic utility over individual rights in people's disclosure of personal information.

The CRTC's more recent Navigating Convergence report addresses privacy in much more detail, reflecting the issue's increasing purchase as a public policy concern. With an entire appendix devoted to "Developing the appropriate regulatory framework to contribute to the protection of the privacy of Canadians," Navigating Convergence offers one of the first instances of the Commission's explicit comment on privacy. Even still, the appendix concludes with the CRTC essentially relinquishing any responsibility for informational privacy online, which they note falls under the purview of the Privacy Act and the Personal Information Protection and Electronic Documents Act (PIPEDA), and thus under the jurisdiction of the Office of the Privacy Commissioner (CRTC 2010, 84-87). While the CRTC acknowledges its own claims to "ex ante regulatory powers under the Telecommunications Act to impose measures to protect privacy," it asserts that there is no present need to add in special provisions for new media (CRTC 2010, 85). Moreover, the report suggests that industry self-regulation would work better than federal regulation anyway: "industry selfregulation is a tool to support privacy protection. Self-regulation is a useful approach when an issue - such as privacy - is too sensitive or resource-intensive to warrant direct government regulation, and where the application of flexible codes based on principles may be more appropriate than strict rules" (CRTC 2010, 85).

Industry self-regulation is also the main strategy proposed in the U.S. by the FTC, where the Commission notes that it would oversee industry protections of informational privacy only secondarily: "Industry self-regulation is an important complement to FTC efforts to respond to consumer protection challenges. Effective self-regulatory organizations have the ability and economic incentives to respond quickly to changes in technology or the marketplace, and can develop workable, practical standards based on their knowledge of their members and their customers. The FTC then can analyze the development of the standards and monitor their implementation to ensure that consumer protections are adequate" (FTC 2008, 31).

Much like the FTC's promotion of industry self-regulation as the primary way to protect informational privacy, the Navigating Convergence report maintains that direct regulation of privacy is not an option for the CRTC at this time. For the single substantial discussion of privacy across the Canadian reports that does not simply frame it as a matter of social privacy, which basically means "risk," Navigating Convergence nonetheless contributes to the overall downplaying of informational privacy as a public issue.

While each report's reticence to propose any interventionist policies around informational privacy may be an indication of the neoliberal context for emergent internet regulation, where business interests often trump those of the public, it also points to gaps in broader social understandings of privacy. On an everyday level, the relative intangibility of informational privacy concerns is what makes them so insidious. As Vincent Mosco's concept of "immanent commodification" emphasizes, social web platforms covertly deploy "new measurement and surveillance technologies to expand the production of media commodities" $(2009,143)$. Mechanisms that work to collect personal data for tracking and profiling work under the surface of these platforms, so that users are not always aware of how the commodification - the transformation of their creative and social production into exchange value for platforms - happens immanently to the system of network sociality. In relation to privacy, "immanent commodification not only produces new commodities; it creates powerful surveillance tools that threaten privacy" (Mosco 2009, 143). These tools include technological means for collecting information about users, such as cookies, flash cookies, beacons, log files and deep packet inspection (OPC 2011, 12-13). The overarching immanent commodification practices that mobilize these technological mechanisms include surveillance, dataveillance, mapping, monitoring and geo-tagging - which all work to amass a variety of personal data within only a small number of commercial and governmental organizations. This concentration of users' information incorporates relatively new sources of personal data like SNS profiles, arranged in new ways like data clouds where web-based services are stored in and made accessible through third parties from remote servers distributed around the globe (OPC 2011, 32).

As the OPC has noted, such new mechanisms, practices and modes of data collection and storage occur across many business models: SNSs that are mainly concerned with marketing; mapping technologies that integrate street-level information with data storage; location-based services for marketing and internet search; the "internet of things," a term that describes a host of new means of rendering objects and persons as data through advanced internetworking technologies, including sensor networks, Internet Protocol version 6, radio frequency identification (RFID) tags, wireless sensors, smart technologies and nanotechnologies; analytics like databases and algorithms; e-Health modules containing personal health records; and newly evolving business models 
based on Web 2.0, third-party applications and cloud computing (OPC 2011, 23). In all these scenarios for data collection, immanent commodification implies that the creation of virtual profiles based on people's data happens without their control or even knowledge, with audiences for such profiles ranging from data brokers, marketers, investigators and monitors, to identity fraud scammers (OPC 2008, 4). In the cases of all of the potential audiences for consumer data, processes of immanent commodification on social web platforms constitute a central logic underlying threats to informational privacy.

While the notion of immanent commodification tends to be absent from the policy documents examined, the Office of the Privacy Commissioner and the Public Interest Advocacy Centre have both produced significant literature in recent years about threats to Canadians' informational privacy online. These reports have attempted to address a broad span of web-based data collection and usage practices, particularly in online social and creative production platforms that invest users with the perception of control over their online profiles. Such intentional profiles built up as part of the labor of UGC are only "the tip of the iceberg" when it comes to personal profiles online (OPC 2008 , 1). It is the hidden practices of the sites' collection and use of personal data in constructing unintentional profiles that undergirds the advertising models that allow these sites to seemingly offer their services for free. This freedom is illusory, however, since user information helps marketers to target ads to users' interests, and to 'inject themselves into conversations and manipulate participants into being favourably disposed towards their products by using loyal consumers' wordof-mouth to communicate a firm's bottom-line to new prospects" (PIAC 2009, 42). In emphasizing the workings of immanent commodification in UGC platforms, informational privacy concerns highlight how contextual integrity might extend beyond apparent networks of friends to include marketers as the unseen audience for both user content and data, as contained in personally identifiable profiles over which users exert little to no control.

In the context of immanent commodification online, proposing persona rights as a normative framework offers some recourse for regulatory bodies to begin considering more robust protection of user rights, while not necessarily compromising economic development. For example, web platforms that offer premium versions of their services already work through user subscriptions - such subscription could be proffered with an eye to protecting persona rights, where paying a fee would enable extra security measures for personal information while simultaneously maintaining a site's revenue flow. Regulatory statues designed to enforce or encourage privacy-enhancing subscription models might also work to enhance public awareness of the ways that personal identity and information is threatened by online marketing. In practice, the combined operation of regulators - both in writing legislation and in educating the public - and web platforms based on subscription rather than advertising models would work to highlight how seemingly "free" platforms are not in fact free, since they come at the hidden cost of compromising users' identity and information.

\subsection{Endorsement}

If less visible marketers and corporate actors can be positioned, through the framework of immanent commodification, as the primary audience for user content and data, then the central function of users is to endorse certain viewpoints, products and network connections. The logic of endorsement, which underlies the marketing practice of collecting user data for online tracking and profiling, threatens not only informational privacy, but also users' intellectual property rights over their own public identities (McGeveran 2009, 1149). Sites tend to obscure how they collect and use personal information; the relative invisibility of these practices constitutes a challenging context in which users might negotiate the way their personas are deployed in online marketing. As McGeveran contends about the inevitable breaches of privacy and property rights given social web platforms' insidious marketing practices, opting out of social networking all together is increasingly difficult as the sites become more ubiquitous: "Doing so would be like a teenager of a previous generation eschewing the telephone. Moreover, opting out of online social networking can abdicate the ability to shape one's own reputation - after all, friends and acquaintances will still discuss the abstainer and tag him or her in photos" (McGeveran 2009, 1127). ${ }^{3}$ Participation in these platforms, in other words, is not optional. In many parts of the world, social web platforms have become ubiquitous sites for the production of culture and more generally, for social interaction and organization.

Given the prevalence of network sociality that hinges on potentially exploitative hidden marketing practices that compromise users' control over their own profiles, McGeveran suggests looking to legal frameworks for new ways of understanding and protecting user rights. In privacy law, he

\footnotetext{
${ }^{3}$ Or, even more immanently, opting out does not prevent people from having their faces recognized and tagged in photos automatically by Facebook's facial recognition technology, rolled out beginning in June 2011.
} 
finds stipulations about the disclosure and handling of personal information, with Canadian privacy regulation particularly aggressive on its stance toward online commercial collection and use of personal data (McGeveran 2009, 1143). Yet privacy legislation does not address the broader implications of the ideal that "an individual should be entitled to control the use of his or her own 'persona' because it is an extension of the self" (McGeveran 2009, 1132). McGeveran thus looks to trademark and competition law to apply some of the regulations around celebrity endorsement to users of social network sites. While trademark law cannot in principle be applied to non-celebrities since they don't enter into contracts specifically for the purpose of using their identities to sell products, it nonetheless highlights how the integrity of identity online is wrapped up in commercial exchange value - in what McGeveran terms "reputational piggybacking" $(2009,1144)$. In this way, the persona can be seen as a commodity, where its value is determined by market exchange, and in turn, where it functions as a kind of property. In persona rights law, McGeveran articulates this understanding of identity-based publicity as a form of property in relation to how that property is constituted and exchanged through social web platforms' appropriation of user privacy. As a "hybrid of privacy and intellectual property law" (McGeveran 2009, 149), persona rights law thus offers a conceptual frame through which to co-articulate user rights to privacy and intellectual property online as part of the overarching endorsement logic of web platforms.

In linking the cultivation of a particular identity through UGC platforms - achieved through user labor that creates value for the platforms themselves - to some notion of rights, the persona rights concept fulfills the important function of yoking privacy concerns to those of intellectual property. The persona rights paradigm's co-articulation of privacy and intellectual property also highlights how "identity control concerns are grounded in two understandings of the interests at stake, one focused more on offense to dignitary interests and the other on a right to compensation for commercial value" (McGeveran 2009, 1149). On commercial UGC platforms driven by immanent commodification, users face the appropriation of their content and personal data in ways that are not always explicit in terms of how they breach privacy and intellectual property rights. While these contextually-dependent meanings of privacy and intellectual property may be usefully articulated together as persona rights, much of the existing literature - including the regulatory reports examined here - deals with each separately. So while I have begun this discussion with privacy as the most salient policy issue leading into the concept of persona rights, I now wish to turn to intellectual property as it comes up across the policy documents. This discussion of intellectual property will keep the immanent commodification of online privacy in mind, however, as it leads into the paper's conclusion about how persona rights as a normative framework implies that these two currently separate areas for regulatory discussion should be more closely tied together.

\section{Persona Rights and Intellectual Property}

In foregrounding the context of online endorsement, the persona rights framework contributes a unique conceptual articulation of privacy and intellectual property in tandem, offering a more holistic approach to the normative protection of user rights under the commercial logic that drives UGC platforms. As Sara Grimes and Leslie Regan Shade have pointed out about children's websites in particular, online data collection not only compromises informational privacy, but "marketing research practices can be seen as infringing upon children's potential intellectual property rights, through their appropriation of the ideas, creativeness, and cultural artefacts children produce and distribute online" $(2005,193)$. This line of argumentation can be extended to users in general, where the cultural significance of UGC activities are often devalued in ways that allow the sites to escape scrutiny in potential breaches of intellectual property rights (for instance, in online product reviews or in message board conversations). This move is important, since the sites rely on the enthusiastic production of content by users for their viability. In extending the discussion of persona rights from within the context of privacy to the context of intellectual property then, this section addresses the question of how user content can be protected from appropriation by UGC platforms as part of their immanent commodification of network sociality.

Intellectual property describes a set of legal claims around creative works, bringing immaterial production under the purview of proprietary interests. Intellectual property claims thus constitute "limited monopolies" over cultural works, where their defining limitations have served as the main grounds for legal intervention (Boyle 1997, 105). While the digital age has seen an explosion of industry and public concern around copyright in particular, in practice, the demarcations between subsets of intellectual property - including copyright, patent, trademark and industrial design have been blurred by the practice of digital reproduction (Vaidhyanathan 2001, 153). The way that digital communication inherently results in a proliferation of copies as part of its transmission mechanism has formed a focal point for certain strands of critical scholarship on intellectual prop- 
erty. Most prominently, legal scholar Lawrence Lessig has framed these immanent copies as having been unfairly targeted by conservative interpretations of U.S. laws that criminalize unlicensed copying. From the point of view of governments and corporations wishing to stimulate innovation, Lessig claims, copyright law should be loosened to promote freedom of expression as essential to democratic citizenship (2008, 28; see also 2004, 9; Benkler 2006, 37; Vaidhyanathan 2011; Berners-Lee 1999, 76).

Persona rights law frames the issue of copyright somewhat differently, from the point of view of the individual user-creator's persona in the context of online endorsement. The U.S. right of publicity - which, along with the tort of appropriation, subtends persona rights law - lends a crucial conception of persona as an individual's inherent proprietary interest in how his or her identity is reproduced, "in controlling the exploitation of one's own identity" (McGeveran 2009, 1109). The idea of one's identity or persona as generating proprietary interest under capital is seen by Carole Pateman (1988) as stemming from the libertarian legacy of self-ownership, which underpins alienable rights to "property in the person" that allow for the person, as private property, to be subject to contracts as part of a logic that she terms "contractarianism". Pateman thus criticizes the notion of property in the person on the grounds that the contracts that bind the person, such as employment contracts, alienate the person-as-laborer's right of self-government while simultaneously demanding labor as a humanistic practice, i.e. a practice marked by self-government and autonomy (Pateman 2002, 47). Her critique of this inherent paradox of contractarianism has only gained credence in recent years with new forms of publicity online that have accelerated the incorporation of persona as property, including the way that SNSs retain licensing rights over user content and expression, amid celebrations of user agency and the democratization of cultural production.

As an iteration of Pateman's characterization of property in the person under contract, the immanent commodification of intellectual property online places user-creators in a bind where their labor contributes to their own identities as "autonomous," while it is also subsumed by extensive intellectual property interests through (voluntary) exploitation by contract. In relation to online news production, Edward Carter (2011) describes how U.S. intellectual property protection has exploded since the implementation of the Digital Millennium Copyright Act (DMCA) in 1998, the provisions of which prohibit any removal or alteration of copyright management information. Carter outlines how various district courts have interpreted this aspect of the DMCA in terms of an enforceable statutory attribution right, where the proprietary nature of persona might be seen to go even further than copyright ownership or licensing contracts to encompass both legal and moral claims under statutory damages (Carter 2011, 189). Yet attribution's implication in the proprietary claims tied to persona tends to follow the contours of the original versus derivative works argument - an argument upon which the DMCA (and the imminent 'Canadian DMCA,' the Copyright Modernization Act) itself hinges - thus obscuring the way that UGC gets appropriated for promotional uses in commercial spaces for network sociality. In this context, a consideration of persona rights as not only a legal but moral claim around UGC labor might point to ways in which internet regulation might reconstitute user rights more generally in terms of user-generated content. The following sections deal with two aspects of such a moral claim implied by the persona rights framework, first having to do with the appropriation of users' intellectual property, and the second about the status of users' intellectual property as original or derivative.

\subsection{Appropriation and Promotion}

Most obviously indicative of the way user content is appropriated to constitute the value of social web platforms, Facebook's success can be attributed to the way it works as a "utility" that isn't yet, but should be, regulated: as danah boyd (2010) has argued, "When people feel as though they are wedded to something because of its utilitarian value, the company providing it can change but the infrastructure is there for good." In this way, Facebook as a utility could be regulated, but so far functions according to monopoly capitalism, allowing it to license user content without much resistance from users who have little choice of opting out, or of controlling the lifecycle of their own content and identity-based profiles.

The way that Facebook capitalizes on its users as often unwitting and un-consenting promotional agents constitutes a form of exploitation, where the surplus value extracted from their everyday communicative exchanges furnishes an immanent commodification system for marketing and advertising. For example, following from McGeveran's persona rights paradigm, James Grimmelman notes that the main obstacle to protecting user rights to both intellectual property and privacy lies in how sites like Facebook capitalize on user identities as publicity: "by sticking purchasetriggered ads in News Feeds with user names and pictures, Facebook turns its users into shills. [...] Facebook has found a way to tap into the commercial value of this 'Long Tail' of micro- 
celebrity" $(2009,1197)$. The site protects this practice through its Terms, which not only entail challenges to informed consent, but enact broader structural moves to define the limits of persona rights to privacy and intellectual property in social online spaces. Effectively, as Pateman suggests, this segmentation of the person's proprietary interests according to contractual stipulations - which involve not only intellectual property but also the privacy of personal information ('private property') as consolidated persona rights - functions to alienate the subject through her or his commodification, where communicative and creative acts are exploited as a kind of labor (e.g. Petersen 2008; Terranova 2000; Lazzarato 1996; Marx 1857/58).

This kind of exploitation is admittedly distributive, as opposed to being concentrated on any individual user, in that sites like Facebook, YouTube and Twitter all require a 'critical mass' of users creating content in order to make them valuable as social web platforms. But these Web 2.0 models share a commodification of users' intellectual property with older versions of network sociality. For instance, commercial websites that solicit user reviews as feedback exercise a marketingbased appropriation of those discourses. Such appropriation marks a deliberate attempt by UGC platforms to devalue the intellectual property rights of users by framing their contributions as part of a conversational discourse, rather than as cultural production. As Gillespie notes about YouTube, the way the site relies on advertising revenue is "certainly downplayed in the specific appeal to regular users, especially to the extent that commercial advertising is not a neat ideological fit with the ethos of the participatory web" (Gillespie 2010,353). Beyond not fitting the ethos of egalitarian participation, an emphasis on the sites themselves as essentially commercial intermediaries also compromises the necessary fiction that user contributions are purely communicational utterances that do not enter into the exchange economy. This is especially apparent in children's websites, where "rarely, if ever, do intellectual property debates position or consider children as cultural producers in their own right" (Grimes and Shade 2005, 193). A similar statement could be made about user-creators on UGC platforms in general, where user contributions get downplayed in order that the sites might retain intellectual property rights over that content.

According to a persona rights framework, however, protecting the personal dignity of users represents a much more expanded view of intellectual property protection by addressing the issue of control over the uses of one's identity. From this broader perspective, UGC in all its incarnations, from blogging to video uploading to the creation of SNS profiles, would be seen as creative work exercised by users as authors, and not simply as consumers. In emphasizing the authorship role of users, the persona rights framework maintains the value of individual identity in commercial web platforms, helping to counter the often exploitative appropriation of user labor. The integrity of identity amid the promotional function of platforms thus represents a kind of moral rights claim, where authorship is expressly non-commercial - it cannot be bought and sold, but rather resides with the creator's persona through the integrity of her or his identity (Murray and Trosow 2007, 63). In protecting the integrity of user-creators' identities, regulation of intellectual property online could be expanded to account for the moral aspects of persona rights claims in best practices standards in promotional uses of UGC.

\subsection{Original and Derivative Works}

A central way in which moral rights are comprised through a widespread downplaying of users' intellectual property claims invokes the distinction between "original" and "derivative" works made in copyright debates. Copyright in fact creates authors by "distinguish[ing] between those who can claim authorship of their work and those who cannot" (Stahl 2009, 55). The move to devalue UGC authorship can be observed across the policy documents that cast user production as "derivative," constituting lower-status cultural production that is potentially threatening to commercial sources of content. Similar to the way that threats to individual privacy posed by commercial activity are barely explored across these documents, discussions of intellectual property seem to bypass the rights associated with user creation in favour of emphasizing users' copyright infractions that threaten commercial interests. The CRTC's Perspectives report, for example, mentions intellectual property only in the context of new media business models for the distribution of broadcasting content: "Content producers may choose to distribute their programming directly to users without licensing it to a third party. For example, a television or web content producer may create a website or RSS subscription fed to allow users to download or stream the content, or third-party aggregators may built content portals, licensing content from creators, as in traditional broadcasting models. The terms of the licensing could include paying nothing for the content (as a user generated content site inviting users to upload audio and audiovisual programming might do) or paying a licensing fee to the producer in return for the right to distribute or broadcast the content" (CRTC 2008, 47). 
This passage indicates the CRTC's fidelity to a sender-receiver model of broadcasting, which indeed underlies the new media exemption order in itself, where users are depicted as wholly distinct from producers or creators, who retain exclusive access to intellectual property protection.

As the Perspectives report makes clear, user content does not pose intellectual property concerns, which arise only in professional contexts with practices such as digital watermarking - "of particular interest to new media companies seeking to manage and protect their copyright content as it is distributed across the Internet" (CRTC 2008, 45) - strict controls over mobile content - "mobile platforms offer a safer distribution platform for content from the perspective of protecting rights holders from unauthorized use" (CRTC 2008, 42) - and Canadian cultural preservation - "the maintenance of Canada as a separate rights market for new media broadcasting is critical to the continued health of the Canadian broadcasting system" (CRTC 2008, 61). This last concern for the protection of a unique Canadian approach to intellectual property rights appeals to the CRTC's stated public function, but ultimately uses nationalistic rhetoric to promote a more narrow designation of legitimate rightsholders.

The Commission again expresses intellectual property as juxtaposed alongside Canadian national identity in Navigating Convergence, under the discussion of Canada's National Digital Strategy. A National Digital Strategy, which has been lacking in Canada, is currently taking shape through a series of nationwide government consultations that began in May 2010 with the launch of an online consultation portal. The CRTC understands its regulatory role in this National Digital Strategy as extending beyond its "existing toolset" to encompass "issues in relation to matters of taxation, copyright, privacy, spectrum management and convergence of broadcasting and Telecommunications industries, among others" (CRTC 2010, 48). But within this range of issues mentioned, the copyright threat of piracy is singled out: "A key challenge to the health of the broadcasting system is piracy, which cannot be understated. Piracy has fundamentally changed the music industry, forcing artists to seek ways of monetizing their work outside of traditional copyright structures. [...] As noted above, where a combination of regulatory and market forces creates hurdles for users to access content, a free alternative will be available and attractive. [...] Other jurisdictions have sought a solution to piracy through obligations on ISPs to, for example, deny service to frequent infringers. A Canadian solution to ensuring the continued viability of the Canadian broadcasting industry may require a partnership with ISPs in one form or another" (CRTC 2010, 48).

This vilification of piracy, and thus support of traditional models and producers of cultural production, is perhaps unsurprising for a regulatory agency that seeks a synergistic "partnership with ISPs in one form or another." And it is also in line with the report's emphasis on market competition - "a national digital strategy might also consider the economics of competition in the communications sphere" (CRTC 2010, 65) - as well as the global competition rhetoric that betrays an underlying economic valuation of Canadian cultural sovereignty: "Finally, to better compete in a global, digital environment, Canadians need the ability to actively participate in the creation and presentation of, and see themselves reflected in, Canadian stories. A world-leading broadband network infrastructure is not an end in itself. The "pipes" are only useful inasmuch as they are used to deliver services, applications and content to Canadians. It will be necessary to ensure that Canadians can contribute to and see themselves in stories that are accessible on multiple digital platforms, whether from private, public or community sectors. [...] Strengthening and promoting Canadian content, services and applications in a global digital environment will enhance Canada's position in a global digital information economy" (CRTC 2010, 49).

The invocation of active participation and accessibility for citizens feels like a conciliatory gesture within the context of the report's overall emphasis on infrastructure development and industry protections, and indeed, within the statements championing Canada's competition in "a global digital information economy" that bookend this section. Moreover, it reveals that the previous discussion of copyright infractions and piracy upholds a one-sided view of intellectual property rights as belonging to traditional media producers, and not to the Canadian citizens expected to contribute to national representations.

Consistent with the CRTC reports, it seems that most of the policy documents interpret intellectual property conservatively, as having to do with professional content creation and not UGC. The Ofcom report on social networking in fact never mentions intellectual property, following from its conception of social networking as not included in the designation of UGC - even though users are said to "create their own online page or profile and to construct and display an online network of contacts" (Ofcom 2008, 1). The FTC also fails to consider UGC as intellectual property, instead concentrating its discussion on user concerns over proprietary technologies and digital rights management (FTC 2008, 17). As such, the implications of UGC for intellectual property remain bound by traditional conceptions of professional rightsholders. 
The most detailed discussion of the dynamic between original and derivative works comes from the OECD report, which appears to claim that UGC constitutes a challenge to traditional intellectual property frameworks: "Copyright issues related to UCC arise in a number of different ways. At the outset, it may be helpful to distinguish between 'original works' created by users and works created by users from pre-existing works (commonly called 'derivative works'). Original works identified as UCC raise the same copyright issues as original works created under other circumstances and can present relatively familiar issues of control, commercial exploitation, and protection in the online environment. Derivative UCC works (such as fan fiction or a blog that incorporates some or all of a protected work) highlights a difficult copyright issue, i.e. whether such derivative works are acceptable uses permitted by the respective jurisdiction's exceptions and limitations (sometimes referred to as 'fair use') or an unlawful infringement of the creator's exclusive rights" (OECD 2007, 44).

The initial pronouncement that copyright issues "arise in a number of different ways" seems to set up an argument for the reevaluation of copyright according to newer forms of production in UGC. But this section goes on to elaborate on only two contexts that inform copyright issues original versus derivative works - with the conclusion that original works act as professional content and that derivative works such as remixes are subject to the copyright limitations specific to each OECD member country. So despite a more explicit analysis of the intellectual property issues around UGC, the OECD report maintains that copyright protections only extend to the originals used in the derivative, and not to the derivative itself as its own original production. This devaluation of the originality in derivative works of UGC is accompanied by the definition of original works of UGC as essentially the same as professional content, entailing "the same copyright issues as original works created under other circumstances," and "relatively familiar issues of control, commercial exploitation, and protection in the online environment."

While at first seeming to say that UGC requires new conceptions of intellectual property online, the OECD report ultimately upholds existing rights structures of commercial cultural production. Users must either tread carefully around copyright protections when creating derivative works, or must take on all of the commercial responsibilities of producers when creating original works: "As users are increasingly involved in deriving non-pecuniary and pecuniary benefits from the creation of content, the treatment of these individuals or groups of persons in the face of many applicable legislations may be in question as they evolve from being consumers to actual producers / commercial entities (e.g. in the area of consumer protection, intellectual property rights and taxation)" (OECD 2007, 43).

According to the OECD, users who create original content - especially profitable original content - essentially become "actual producers," bound by a whole set of institutionalized parameters. The language here also serves the function of avoiding the troubling hybridity of the user-producer by maintaining a separation between the two entities. As the report recommends, "Member countries should implement regulatory frameworks that balance the interests of suppliers and users, in areas such as the protection of intellectual property rights, and digital rights management, without disadvantaging innovative e-business model." (OECD 2007, 44). For UGC to be incorporated into these "innovative e-business models," a boundary needs to be maintained between users/consumers and suppliers/producers - allowing for unencumbered commercial exploitation.

As a counter to this exploitative model, the persona rights paradigm imparts an intrinsic value to individual identity, and in turn, to the cultural production that emanates from that identity. Moreover, when users contribute not only their labor of cultural production to commercial platforms' front stage, but also their personal information to backstage processes of immanent commodification, both privacy and intellectual property become more fraught concepts than the regulatory reports tend to acknowledge. Applying a persona rights framework here might help to disentangle the implications of current regulatory debates that do little to address the various facets of user rights in spaces of UGC, even though users are contributing significant economic value. The first step in this process would be for regulators to acknowledge just that - users' privacy and intellectual property protection would not be anathema to commercial development, but on the contrary, would bolster the growth of participatory platforms through rights protections leading to increased transparency of the sites, and therefore trust of the users. As McGeveran claims, designing regulation according to a persona rights framework is meant to enable the healthy growth of social marketing according to best practices, acknowledging the ethical role that platforms play in their structuring of everyday social life. Without regulation in this direction, he cautions, exploitative commercial interests in social web platforms "could cause a variety of problems: disclosure of private information, misleading endorsements, and appropriation of personal identity" (McGeveran 2009, 1165). As such, persona rights offers a productive framework for emerging regulation that considers normative standards for user rights over their content. 


\section{Conclusion: Persona Rights and Regulation}

This paper has sought to apply persona rights as a unique and urgent normative framework to considerations of privacy and intellectual property in regulatory reports from Canada and elsewhere, showing how current debates might be made more comprehensive with regard to user rights. In relation to privacy, reports tend to emphasize social privacy while the commercial harm to identity posed by breaches of informational privacy get short shrift. The persona rights concept addresses this gap by emphasizing the endorsement imperative of social web platforms, and framing identity as a commodity in this context. Second, when considering informational privacy as a regulatory concern, persona rights serves to highlight how immanent commodification - a process largely ignored by neoliberally inflected regulatory reports - spreads in these networked spaces. As a recourse to the dignitary harm posed by immanent commodification, persona rights proposes that an attention to protecting the integrity of users' identities would not compromise economic goals, but would rather bolster the best practices of social web platforms in ways that contribute to the generative value of UGC. The privacy protection model implied by persona rights thus reorients users' relationship to their endorsement role, where users' control over how their personal information and identity get used should be also upheld by regulatory protection. Here, intellectual property is yoked to privacy in terms of control over how one's identity is used; persona rights implies a more robust valuation of user identity that doesn't threaten business interests, but rather augments the total economic, social and cultural value of web platforms.

The way that the persona rights framework co-articulates privacy with intellectual property thus constitutes its most important and unique contribution to regulatory approaches toward UGC. Across the policy reports examined, the idea of rights in UGC platforms seems to be shaped by broader structural inequalities subtending network sociality. Informational privacy, for example, is not often highlighted in discussions of privacy regulation; rather, understandings of privacy are skewed toward the more immediate context of users' social contacts. In this way, Nissenbaum's concept of contextual integrity helps to explain why users seem less concerned with - and in turn, less politically motivated about (OPC 2011,14 ) - breaches of their informational privacy. Similarly, the boundaries of intellectual property rights, framed in the reports as following the categories of original and derivative works, are also difficult to discern in UGC contexts, despite commercial platforms' attempts at delimiting them conclusively. Given the often hidden workings of immanent commodification on these platforms, both privacy and intellectual property rights tend to be downplayed as everyday persona rights issues in people's UGC production.

As McGeveran similarly notes, claiming persona rights becomes further complicated when "social networks cloud the issue of consent" $(2009,1153)$; without informed consent, it is difficult to discern how identities are being used for commercial purposes in ways that threaten dignitary rights of privacy and intellectual property. Taking up this line of argumentation on informed consent might offer some clues into potential regulatory interventions for protecting users' persona rights on social web platforms. Gillespie frames the lack of substantial regulation of such platforms as tied into the discursive resonance of "platforms" as areas of limited liability $(2010,357)$ - a notion that requires critical dismantling in order to move forward with any normative conception of persona rights online. Some kind of normative framework will be necessary in order to draft effective federal legislation, and this needs the contribution that a term like persona rights can offer to the policy debates.

So what might an exercise of legislated persona rights look like for people creating UGC on web platforms? McGeveran projects such a scenario in terms of how persona rights could be wielded in protecting the integrity of identity in light of immanent commodification: "The exercise of persona rights would allow a customer to withhold permission from any or all social marketing, thereby preventing unwanted disclosures, ensuring the accuracy of implied endorsements, and controlling the quantity of messages to avoid spamification" (McGeveran 2009, 1154). While regulation to this effect would require an alteration to the situational contours of privacy in SNSs, it would also require a solution to the issue of informed consent. For users to effectively consent to commercial uses of their information and their content, they need to be aware of exactly how platforms are capitalizing on their UGC. Regulatory protection over the integrity of personal identity would thus entail both top-down policy strategies along with crucial bottom-up processes of education about user rights online and design of less exploitative web platforms (Bennett and Raab 2006). As indicated in the reports examined, issues of privacy and intellectual property are currently under debate, if in fragmentary ways and to varying degrees, in Canada and elsewhere; bringing these two areas together through a persona rights framework would facilitate a more comprehensive scope in emerging regulatory and normative paradigms for protecting user rights. 


\section{References}

Agre, Philip E., and Marc Rotenberg. 1997. Technology and Privacy: The New Landscape. Cambridge: MIT Press.

Allen, Anita L. 1999. Coercing Privacy. William and Mary Law Review 40 (3): 723-757.

Benkler, Yochai. 2006. The Wealth of Networks: How Social Production Transforms Markets and Freedom. New Haven: Yale University Press.

Bennett, Colin, and Charles Raab. 2006. The Governance of Privacy: Policy Instruments in Global Perspective. Cambridge: MIT Press.

Berners-Lee, Tim. 1999. Weaving the Web. New York: HarperCollins.

Boyle, James. 1997. A Politics of Intellectual Property: Environmentalism for the Net? Duke Law Journal 47 (1): 87-116.

boyd, danah. 2010. Facebook is a Utility; Utilities Get Regulated: Apophenia, May 15. Accessed June 20, 2011. http://www.zephoria.org/thoughts/archives/2010/05/15/facebook-is-a-utility-utilities-get-regulated.html

Campbell, John Edward, and Matthew Carlson. 2002. Panopticon.com: Online Surveillance and the Commodification of Privacy. Journal of Broadcasting and Electronic Media 46 (4): 586-606.

Canadian Radio-television and Telecommunications Commission (CRTC). 2010. Navigating Convergence: Charting Canadian Communications Change and Regulatory Implications. Ottawa: CRTC. Accessed June 26, 2011. http://www.crtc.gc.ca/eng/publications/reports/rp1002.htm

Canadian Radio-television and Telecommunications Commission (CRTC). 2009. About the CRTC. Accessed May $12,2011$. http://www.crtc.gc.ca/eng/backgrnd/brochures/b29903.htm

Canadian Radio-television and Telecommunications Commission (CRTC). 2008. Perspectives on Canadian Broadcasting in New Media: A Compilation of Research and Stakeholder Views. Ottawa: CRTC. Accessed June 26, 2011. http://www.crtc.gc.ca/eng/media/rp080515.htm

Carter, Edward L. 2011. Copyright Ownership of Online News: Cultivating a Transformation Ethos in America's Emerging Statutory Attribution Right. Communication Law and Policy 16 (2): 161-195.

Debatin, Benjamin, Jennette P. Lovejoy, Ann-Kathrin Horn, and Brittany N. Hughes. 2009. Facebook and Online Privacy: Attitudes, Behaviors and Unintended Consequences. Journal of Computer-Mediated Communication 15: 83-108.

Federal Trade Commission (FTC). 2008. Protecting Consumers in the Next Tech-ade. Washington, DC: FTC. Accessed September 3, 2011. www.ftc.gov/os/2008/03/P064101tech.pdf

Floridi, Luciano. 2005. The Ontological Interpretation of Informational Privacy. Ethics and Information Technology 7 (4): 185200.

Gates, Kelly, and Shoshana Magnet. 2007. Communication Research and the Study of Surveillance. The Communication Review 10: 277-293.

Gillespie, Tarleton. 2010. The Politics of 'Platforms'. New Media \& Society 12 (3): 347-364.

Grimes, Sara, and Leslie Regan Shade. 2005. Neopian Economics of Play: Children's Cyberpets and Online Communities as Immersive Advertising in NeoPets.com. International Journal of Media \& Cultural Studies 1 (2): 181-198.

Grimmelman, James. 2009. Saving Facebook. lowa Law Review 94: 1137-1206.

Hamilton, Sheryl. 2009. Impersonations: Troubling the Person in Law and Culture. Toronto: University of Toronto Press.

Introna, Lucas. 1997. Privacy and the Computer: Why We Need Privacy in the Information Society. Metaphilosophy 28 (3): 259-275.

Kerr, Ian, Valerie Steeves, and Carole Lucock, eds. 2009. Lessons from the Identity Trail: Anonymity, Privacy and Identity in a Networked Society. Oxford: Oxford University Press.

Lawson, Philippa. 1999. Privacy in Canada: A Public Interest Perspective. Address to the Riley Conference on Privacy and Bill C-54. February 23. Ottawa: Public Interest Advocacy Centre. Accessed August 14, 2011. http://www.piac.ca/privacy/privacy in canada a public interest perspective/

Lazzarato, Maurizio. 1996. Immaterial Labor. In Radical Thought in Italy: A Potential Politics, edited by Michael Hardt and Paolo Virno, 133-147. Minneapolis: University of Minnesota Press.

Lessig. Lawrence. 2008. Remix: Making Art and Commerce Thrive in the Hybrid Economy. New York: Penguin.

Lessig, Lawrence. 2004. Free Culture: How Big Media Uses Technology and the Law to Lock Down Culture and Control Creativity. New York: Penguin.

Livingstone, Sonia. 2008. Taking Risky Opportunities in Youthful Content Creation: Teenagers' Use of Social Networking Sites for Intimacy, Privacy and Self-expression. New Media \& Society 10 (3): 393-411.

Marx, Karl. 1857/58. Grundrisse. London: Penguin.

McGeveran, William. 2009. Disclosure, Endorsement, and Identity in Social Marketing. University of Illinois Law Review 2009 (4): 1105-1166

Mosco, Vincent. 2009. The Political Economy of Communication, Second Edition. Thousand Oaks, CA: Sage.

Murray, Laura J., and Samuel E. Trosow. 2007. Canadian Copyright: A Citizen's Guide. Toronto: Between the Lines.

Nippert-Eng, Christena. 2011. Islands of Privacy. Chicago: University of Chicago Press.

Nissenbaum, Helen. 2010. Privacy in Context: Technology, Policy, and the Integrity of Social Life. Stanford, CA: Stanford University Press.

Nissenbaum, Helen. 2004. Privacy as Contextual Integrity. Washington Law Review 79: 101-139.

Organisation for Economic Co-operation and Development (OECD). 2007. Participative Web and User-Created Content: Web 2.0, Wikis and Social Networking. London: OECD. Accessed June 26, 2011. http://213.253.134.43/oecd/pdfs/browseit/9307031E.pdf

Ofcom: The Federal Office of Communication. (2008). Social Networking: A Quantitative and Qualitative Research Report into Attitudes, Behaviours and Use. London: Ofcom. Accessed June 26, 2011. http://www.ofcom.org.uk/advice/media literacy/medlitpub/medlitpubrss/socialnetworking/report.pdf

Office of the Privacy Commissioner of Canada (OPC). 2011. Report on the 2010 Office of the Privacy Commissioner of Canada's Consultations on Online Tracking, Profiling and Targeting and Cloud Computing. Ottawa: Office of the Privacy Commissioner.

Office of the Privacy Commissioner of Canada (OPC). 2008. Meeting of Two Worlds: the Legal and Information Technology (IT) Universes - Online Identity: Between Privacy and Virtual Profiles. Ottawa: Office of the Privacy Commissioner. 
Pateman, Carole. 2002. Self-Ownership and Property in the Person: Democratization and a Tale of Two Concepts. The Journal of Political Philosophy 10 (1): 20-53.

Pateman, Carole. 1988. The Sexual Contract. Stanford, CA: Stanford University Press.

Petersen, Søren Mørk. 2008. Loser Generated Content: From Participation to Exploitation. First Monday 13 (3). Accessed May 12, 2010. http://firstmonday.org/htbin/cgiwrap/bin/ojs/index.php/fm/article/view/2141/1948

Pickard, Victor. 2007. Neoliberal Visions and Revisions in Global Communications Policy From NWICO to WSIS. Journal of Communication Inquiry 31 (2): 118-139.

Public Interest Advocacy Centre (PIAC). 2009. A "Do Not Track List" for Canada? Ottawa: Public Interest Advocacy Centre. Accessed April 2, 2011. http://www.piac.ca/files/dntl final website.pdf

Raynes-Goldie, Kate. 2010. Aliases, Creeping, and Wall Cleaning: Understanding Privacy in the Age of Facebook. First Monday 15 (1). Accessed September 3, 2011.

http://firstmonday.org/htbin/cgiwrap/bin/ojs/index.php/fm/article/viewArticle/2775/2432

Stahl, Matt. 2009. Privilege and Distinction in Production Worlds: Copyright, Collective Bargaining, and Working Conditions in Media Making. In Production Studies: Cultural Studies of Media Industries, edited by Vicki Meyer, Miranda Banks, and John Caldwell, 54-67. New York: Routledge.

Tavani, Herman. 2008. Informational Privacy: Concepts, Theories, and Controversies. In The Handbook of Information and Computer Ethics, edited by Kenneth Himma and Herman Tavani, 131-164. Hoboken: Wiley.

Terranova, Tiziana. 2000. Free Labor: Producing Culture for the Digital Economy. Social Text 6318 (2): 33-58.

Vaidhyanathan, Siva. 2001. Copyrights and Copywrongs: The Rise of Intellectual Property and How it Threatens Creativity. New York: NYU Press.

Warren, Samuel, and Louis Brandeis. 1890. The Right to Privacy. Harvard Law Review 4 (5): 193-220.

\section{About the Author}

Tamara Shepherd

$\mathrm{PhD}$ candidate in the Joint Doctorate in Communication at Concordia University in Montréal, Canada. She has published and presented papers on aspects of labor in user-generated content and new media policy, from a feminist political economy perspective. Her dissertation is titled "Persona Rights in Young People's Labour of Online Cultural Production: Implications for New Media Policy" (2012). 